\title{
HOMENAJE A JAVIER GARCÍA-BELLIDO.
}

\section{Gerardo Roger Fernández}

Arquitecto, Urbanista y Técnico de Ordenación del Territorio.

Profesor de Urbanística de la Universidad Politécnica de Valencia

Valencia, España

\section{Remisión Artículo: 15-1-2007}

Palabras Claves: LRAU, PGOU Almería, DGOU y OT de la Generalidad Valenciana, del desarrollismo al urbanismo de la democracia.

Me piden que escriba un breve texto personal acerca de mi relación personal y profesional con Javier García-Bellido. Nada más grato me podrían haber encargado, aunque no menos nostálgico y emotivo, pues comporta resumir una profunda y afectiva experiencia humana iniciada hace mucho tiempo.

De hecho, conocí a Javier a finales de los años 70. En aquél tiempo, yo ocupaba el cargo de Presidente del Colegio de Arquitectos en Almería y habiéndose aprobado los Reglamentos que desarrollaban la Ley del Suelo vigente de 1976, consideré oportuno ponerme en contacto con los responsables técnicos del Ministerio con el objeto de organizar un Curso explicativo de las nuevas técnicas y conceptos jurídico-urbanísticos que iban a condicionar el planeamiento y la gestión futura y destinado a los colegiados almerienses.

Fue entonces cuando, sorprendido, descubrí el generoso y desbordante entusiasmo por parte de aquél singular funcionario estatal en el apoyo y colaboración que demostró en la formulación y programación del Curso, colaboración que permitió iniciar una larga relación personal de amistad que vino a cristalizar un tiempo después.

De hecho, en el año 82 tuvimos de nuevo otra ocasión de colaborar profesionalmente, esta vez con motivo de la redacción del Plan General de Ordenación Urbana de Almería cuya formulación técnica tuve la oportunidad de dirigir. Entonces, como Subdirector del Instituto de Estudios de Administración Local y bajo la supervisión de Luciano Parejo, a la sazón Director del mismo, Javier se "volcó" con nosotros no solo en explicarnos la aplicación práctica de los nuevos instrumentos legales para conseguir los fines públicos deseados y, en concreto, las características de su primera gran aportación al Derecho Urbanístico, es decir, las transferencias de aprovechamiento urbanístico (las TAU) para la gestión en Suelo Urbano, sino también recomendándonos a profesionales expertos que pudieran complementar solventemente al Equipo, como, por ejemplo, al excelente economista Javier Russinés para la elaboración del Estudio Económico-Financiero del Plan.

La implicación de Javier fue tan intensa, que incluso se quedaba algunas noches con nosotros para definir y diseñar, en concreto, las técnicas por Zonas de Ordenación, llegando a conocer tanto o más que el propio Equipo redactor, los problemas y oportunidades de la ciudad y sus barriadas. De hecho, además de su desbordante laboriosidad profesional y la mutua simpatía 
que nos unió, tal vez, que su vivienda familiar en Madrid estuviera localizada en la calle Cuevas del Almanzora, Municipio de vieja tradición arqueológica de Almería, también influyera en ello. Recuerdo aquella pequeña casa con las "librerías" colgadas del techo del pasillo como otra habilidad de Javier en sacar eficacia al limitado espacio doméstico y a su ya amplio bagaje bibliográfico. En cualquier caso, terminó por consolidarse y prosperar una continuada relación personal, más egoísta por mi parte, pues aprovechaba su tradicional amabilidad para "sonsacarle" respuestas solventes a cuantas dudas o cuestiones me animaba a trasladarle.

Afortunadamente, y seguramente no por casualidad, nuevas oportunidades de colaboración profesional surgieron en el horizonte. De hecho, a través de la responsabilidad de la Dirección General de Urbanismo y Ordenación del Territorio de la Generalitat Valenciana que tuve el honor de asumir entre 1990 y 1995 (y en la que Javier tuvo, según supe posteriormente, también algo que ver), acometimos la formulación de la Ley Reguladora de la Actividad Urbanística, más conocida como la LRAU. En concreto, se conformó un Equipo redactor de la Ley integrado por Luciano Parejo, Francisco Blanc y Silvestre Martínez, el cual, bajo mi dirección y la inestimable consultoría y aportaciones de Javier, llegó a producir un marco jurídico innovador en el Derecho Urbanístico, español y valenciano, que venía a quebrar el viejo monopolio preindustrial que atribuía la facultad de urbanizar, con carácter exclusivo, a la propiedad mayoritaria del suelo a través de la aplicación de un sistema concurrencial en el cual, se seleccionaba al agente-urbanizador en condiciones de competencia y publicidad, bajo control de la Administración pública.

De nuevo, sus aportaciones basadas en el amplio conocimiento que disponía del derecho comparado europeo y su enorme clarividencia en la definición de los problemas, todo ello en el marco de la amistad y la perfecta sintonía que, desde hacía años unía al grupo de trabajo, vino a facilitar muchos las cosas. Como vemos, nuevamente la presencia física y sobre todo intelectual de Javier fue absolutamente determinante en la creación de una nueva concepción del urbanismo basada en la separación del derecho de propiedad del derecho a la ejecución desde el refuerzo de la función pública del mismo.

De hecho, su impulso en todas las nuevas concepciones que últimamente han venido caracterizando al Urbanismo español, ya desde la Comisión de Expertos que creó el Ministro Josep Borrell en los años 93 y 94, Comisión de la que fue Secretario, así como desde la Revista Ciudad y Territorio Estudios Territoriales de la que fue Director, han sido siempre paradigmáticas, debiéndose a él, en gran medida, su difusión y asunción por diversos sectores, no siempre proclives a la innovación doctrinal y, en concreto, por algunas legislaciones autonómicas posteriores. Es más, cuando las fuerzas parecían flaquear ante los diversos ataques a los que el nuevo escenario innovador se ha visto sometido por causa, unas veces del insuficiente conocimiento o de la mala aplicación del mismo y otras, a causa de intereses "menos claros", era Javier el que levantaba el ánimo colectivo y lo impulsaba a seguir defendiendo las posiciones progresistas conquistadas.

Por último, no podría faltar el impulso de Javier en la formulación de la Reforma de la Ley de Suelo del Estado que una Comisión de Expertos viene realizando, bajo la dirección de Marcos Vaquer y el liderazgo de Luciano Parejo ( $\mathrm{y}$ a la que tengo la fortuna de pertenecer), a la que ha venido a aportar, incluso, concepciones más avanzadas, en la esperanza que las inercias sociales aún pudieran ser doblegadas de manera más anticipada. 
De hecho, resulta impensable comprender la actual urbanística española sin contar con las fundamentales y esenciales aportaciones, analíticas e instrumentales que nos legó Javier García-Bellido, siempre desde un explícito posicionamiento de independencia intelectual e ideológica y también siempre desde expresos y comprometidos criterios de defensa del interés público y general.

En fin, en estas breves palabras no quiero dejar de resaltar una trascendental faceta que caracterizaba a Javier y que no es otra que su enorme capacidad pedagógica, entreverada de la, ya señalada generosidad intelectual.

Esta capacidad se ponía de manifiesto, por ejemplo, en la citada dirección de la revista Ciudad y Territorio, no solo a través de sus editoriales, siempre valientes e inteligentemente críticas y comprometidas con la realidad urbana, con sus regulaciones jurídicas y con los paradigmas territoriales y urbanos al uso, si bien, siempre respetuosos con las posiciones contrarias, 0 cuando abría la revista a cualquier aportación disciplinar de interés que, previo contraste democrático a través de un comité de especialistas, resultase aconsejable su publicación para enriquecimiento y disponibilidad cultural de sus lectores y estudiosos del urbanismo.

Pero recordando algunas vivencias personales, esa fundamental capacidad la podía constatar en las numerosas ocasiones que tuve la fortuna de intervenir conjuntamente con Javier en clases y conferencias de diversos Master y Cursos de Urbanismo.

De hecho, cuando tenía el honor y la satisfacción de presentarle en esos foros, siempre reseñaba, en primer lugar, la extraordinaria generosidad intelectual ya señalada, como demostraba continuamente a través de la puesta a disposición de quien lo quisiera de todas sus reflexiones y propuestas y sin guardarse nada para sí mismo ni para uso propio. En segundo lugar, ponía de manifiesto una característica fundamental de los divulgadores y de la que Javier disponía sobradamente y que no es otra que aquella virtud de los viejos maestros de "enseñar deleitando". De hecho, los asistentes a cualquier conferencia o disertación de Javier, son testigos de su explícita capacidad pedagógica y de la expresa amenidad de las mismas, lo que contribuía, aún más, a la mejor transmisión de sus vastos conocimientos. Esa capacidad pedagógica, junto a su generosidad ya reseñada, se explicita claramente en el lúcido prólogo de mi libro "Del desarrollismo al Urbanismo de la Democracia" publicado por el Instituto de Estudios Almerienses en 1994 y que Javier tuvo la gentileza de realizar y yo el agradecimiento de que lo hiciera.

Estas son, en fin, unas breves reflexiones y recuerdos de quien se reconoce como amigo y deudor de Javier García-Bellido, de cuya generosidad y magisterio fui conocedor desde finales de los años 70, después con la formulación del Plan General de Almería, que continuó en los 90 desde la Dirección General de Urbanismo de la Generalitat Valenciana y se terminó de cristalizar a través de una afectiva, vitalista y respetuosa amistad con él y a través de él, con Consuelo, su mujer, y que se mantiene hasta la actualidad.

Sirvan, pues, estas palabras como un humilde y entrañable homenaje a aquél "arquitecto en agraz" a quien Antonio García y Bellido, su padre, dedicó el imprescindible libro "Urbanística de las Grandes Ciudades del Mundo Antiguo", a éste "arquigado", en lúcida terminología de nuestro común amigo y maestro, Luciano Parejo. 
Desgraciada y dolorosamente, de manera sobrevenida, se nos ha ido Javier cuando, como siempre, a "pie de obra", se encontraba impartiendo docencia, esta vez en la Carlos III, empecinando siempre su labor como servidor de la función pública del urbanismo. Se nos ha ido el "rey de los arquigados". Esperemos que sus amigos y colaboradores podamos ser capaces de continuar su legado.

Es lo que él esperaría de nosotros y lo mínimo que por él debemos hacer. 